\title{
Hypermnesia: Age-related differences between young and older adults
}

\author{
ROBERT L. WIDNER, JR. \\ Georgia Institute of Technology, Atlanta, Georgia \\ HAJIME OTANI \\ Central Michigan University, Mt. Pleasant, Michigan \\ and \\ ANDERSON D. SMITH \\ Georgia Institute of Technology, Atlanta, Georgia
}

\begin{abstract}
Hypermnesia is a net improvement in memory performance that occurs across tests in a multitest paradigm with only one study session. Our goal was to identify possible age-related differences in hypermnesic recall. We observed hypermnesia for young adults using verbal (Experiment 1) as well as pictorial (Experiment 2) material, but no hypermnesia for older adults in either experiment. We found no age-related difference in reminiscence (Experiments 1 and 2), though there was a substantial difference in intertest forgetting (Experiments 1 and 2). Older, relative to young, adults produced more forgetting, most of which occurred between Tests 1 and 2 (Experiments 1 and 2). Furthermore, older, relative to young, adults produced more intrusions. We failed to identify a relationship between intrusions and intertest forgetting. We suggest that the age-related difference in intertest forgetting may be due to less efficient reinstatement of cues at test by older adults. The present findings reveal that intertest forgetting plays a critical role in hypermnesic recall, particularly for older adults.
\end{abstract}

Hypermnesia is a net improvement in memory performance across repeated test trials in the absence of additional study sessions (see, e.g., Erdelyi, 1996; Payne, 1987; Roediger \& Challis, 1989; Shapiro \& Erdelyi, 1974). Two factors are responsible for this phenomenon: reminiscence and forgetting. Reminiscence is the retrieval of study list items on subsequent tests that have not been recalled on previous attempts, whereas forgetting occurs when items retrieved on initial attempts fail to be retrieved on subsequent attempts. When reminiscence is greater than forgetting, there is a net increase in recall performance (i.e., hypermnesia), and when forgetting is greater than reminiscence, there is a net loss in performance. Hypermnesia

We thank Mathew Erdelyi and Steve Smith for their helpful comments on an earlier draft of this manuscript. Experiment 1 was conducted while the first author was an NIH postdoctoral research fellow in the Cognitive Aging program at the Georgia Institute of Technology (Training Grant AG00175-09). Experiment 2 was conducted while the first author was a National Science Foundation Minority Postdoctoral Fellow at New York University. This research was supported in part by a grant to the first author from the Southeastern Center for Applied Cognitive Aging Research, one of the Edward R. Roybal Centers for Research in Applied Gerontology (Grant AG11715-02); by the National Science Foundation; and by a Center for Excellence Award from the College of Graduate Studies at Central Michigan University given to the General Master's Program. Address correspondence to R. L. Widner, Jr., Department of Psychology, University of Colorado, Colorado Springs, CO 80933 or Institute of Cognitive Science, Muenzinger Psychology Building, Campus Box 344, University of Colorado, Boulder, CO 80309 0344 (e-mail: rwidner@brain.uccs.edu). is a relatively reliable phenomenon (e.g., particularly when pictures are used as to-be-remembered stimuli), in that it has been observed with a variety of stimuli and under varied conditions (see Payne, 1987, for a review). It is intriguing in that one expects recall performance to be optimal immediately after acquisition and not at some later point (cf. the Ebbinghaus decay function; Ebbinghaus, $1885 / 1964)$. In the present study, our goal was to identify possible age-related differences in hypermnesic recall.

A substantial amount of research has focused on reminiscence with little directed at forgetting. To illustrate, the cumulative recall level hypothesis (see, e.g., Roediger \& Challis, 1989; Roediger, Payne, Gillespie, \& Lean, 1982; Roediger \& Thorpe, 1978) suggests that hypermnesia is a function of the asymptotic level of recall. That is, a relatively large number of items are available for recall, but, for whatever reason (e.g., not enough time to report items), they are not recalled. Such an analysis assumes that the amount of intertest forgetting remains the same irrespective of the type of encoding engaged in at study (e.g., Payne, 1986) or that intertest forgetting does not affect hypermnesic recall levels (e.g., Roediger, 1982). We agree with McDaniel, Moore, and Whiteman (1998) that to understand hypermnesia fully, one must examine reminiscence as well as forgetting. Thus, of particular interest in the present study is the role of intertest forgetting in this phenomenon.

In the present study, we expected no age-related difference in reminiscence levels. This expectation was based 
on three findings: (1) The use of unrelated study items, as in the present study, encourages item-specific encoding (see, e.g., Burns, 1993; Klein, Loftus, Kihlstrom, \& Aseron, 1989); (2) age-related differences are minimal when item-specific encoding is used (e.g., Witte, Freund, \& Sebby, 1990); and (3) item-specific encoding (e.g., in a pleasantness rating task) increases the distinctiveness of an item from other items held in memory (e.g., Hunt \& McDaniel, 1993) and increases the likelihood of observing reminiscence (e.g., Burns, 1993; Klein et al., 1989).

We did expect a relatively large age-related difference in intertest forgetting, such that older adults would exhibit greater forgetting than would young adults. This expectation was based, in part, on the hypothesis, entertained by Erdelyi (1982) and Roediger (1982), that elaboration, in the depth-of-processing sense (Craik \& Tulving, 1975), is the controlling factor in hypermnesia. Similarly, Klein et al. (1989) assert that relational processing (e.g., sorting into taxonomic categories) increases similarities among items within a list (e.g., Hunt \& McDaniel, 1993). According to Klein et al., relational processing reduces intertest forgetting (see Burns, 1993, for a similar finding). Thus, once an item has been retrieved from memory it is likely to be retrieved on subsequent attempts if it is made part of an organized retrieval network (similar to the "incrementing" concept in the search of associative memory model; Raaijmakers \& Shiffrin, 1980). Even though we encouraged use of item-specific encoding in the present study, we assumed that young adults would engage in spontaneous elaboration of tobe-learned material (cf. Tulving, 1962, 1964), whereas older adults would be less likely to engage in such processing (cf. Worden \& Meggison, 1984). Not only are older adults less likely to engage in elaborative processing, but they are less efficient at it, relative to young adults, when they do (see, e.g., Witte et al., 1990). Further, elaborative processing reduces intertest forgetting (see, e.g., McDaniel et al., 1998; Witte et al., 1990). Thus, for several reasons, it follows that older adults, relative to young adults, should exhibit greater intertest forgetting.

\section{EXPERIMENT 1}

For all participants, encoding was biased so that it was primarily item specific. This was accomplished by using unrelated study words and by having participants generate oral, rather than written, free recall reports. We reasoned that oral reports would reduce the amount of relational processing that might occur relative to when items are visually available for further processing, as they would be under written recall conditions.

We know that older adults, relative to young adults, exhibit a greater number of intrusions under free recall conditions (see, e.g., Koriat, Ben-Zur, \& Sheffer, 1988). We hypothesized that, to the extent that intrusions play a role in intertest forgetting, the longer the intertest interval, the less the negative effect that intrusions should have on hypermnesic recall (e.g., Smith \& Vela, 1991; fluctuation hypothesis). We examined this possibility by manipulating the length of the intertest interval.

\section{Method}

Participants. Forty undergraduates (mean age $=19.26$ years; $S D=2.56$ ) enrolled in psychology classes at Central Michigan University and 40 older adult residents (mean age $=69.19 ; S D=3.86$ ) in the Atlanta area participated in the present study (some older adults were alumni of the Georgia Institute of Technology). The undergraduates participated to fulfill course requirements, and the older adults were paid $\$ 10$. The participants self-rated their health on a scale that ranged from $1=$ excellent health to $5=$ poor health, with a mean rating for young adults of $1.35(S D=.48)$ and for older adults, $1.85(S D=.66)[t(78)=3.86, p<.001]$. Education levels were 14.43 years $(S D=1.38)$ for the young adults and $15.70(S D=$ $.97)$ for the older adults $[t(78)=4.80, p<.001]$.

Stimuli and Apparatus. The participants were asked to study a list of 42 words, with each word being four letters in length, monosyllabic, and having a high frequency of occurrence in the English language ( $M=285$; range, 100-967; Kučera \& Francis, 1967). The mean imagery value for these words was 5.17 , with a range of 3.18 6.32 (Toglia \& Battig, 1978). The stimuli were presented in white lowercase letters against a black background on a computer monitor. A distractor task required the participants to count backwards, by threes, from an experimenter-provided three-digit number. Finally, a tape recorder was used to record free recall reports.

Procedure. Participation occurred individually. Each participant was presented with a list of words, one at a time, and informed that he/she must silently study the words for three to-be-presented free recall tests. Each presented word remained on the monitor for $5 \mathrm{sec}$, with an interstimulus interval of $500 \mathrm{msec}$. After having studied all of the words, the participants engaged in a 1-min distractor task, after which they heard a beep that signaled the start of the first 5 -min recall period.

Upon completion of the first recall trial, individuals in the immediate condition were asked to begin their second recall trial (i.e., no intertest interval). Individuals in the delay condition were provided with 15 -min intervals during which they were instructed to think about the study items in anticipation of the next recall trial. We used 15-min intervals to maximize hypermnesic recall levels (in accord with the total time hypothesis; see Roediger \& Thorpe, 1978). We did not provide feedback; if a participant asked whether he/she had already reported an item during a recall session, the experimenter responded with some neutral comment (e.g., "I'm not sure").

\section{Results and Discussion}

A .05 significance level was adopted for all statistical tests unless noted otherwise, and all comparisons were planned and two-tailed.

Recall performance. The design was a $2 \times 2 \times 3$ mixed analysis of variance (ANOVA) with age (young vs. old) and interval (immediate vs. delay) varied between participants and test (Test 1 vs. Test 2 vs. Test 3 ) varied within participants. The dependent measure was the number of items recalled correctly (see Table 1).

The analysis revealed a main effect of age, such that recall by young adults was greater than that of older adults $(M \mathrm{~s}=17.56$ and 12.22 , respectively) $[F(1,76)=28.63$, $\left.M S_{\mathrm{e}}=59.80\right]$. This finding replicated a frequently observed pattern of memory performance: greater recall by young adults than by older adults (see, e.g., Kausler, 1994). Age interacted with test $\left[F(2,152)=19.17, M S_{\mathrm{e}}=3.67\right]$; 
Table 1

\begin{tabular}{|c|c|c|c|c|c|c|c|c|}
\hline \multirow[b]{2}{*}{ Age } & \multirow[b]{2}{*}{ Condition } & \multicolumn{2}{|c|}{ Test 1} & \multicolumn{2}{|c|}{ Test 2} & \multicolumn{2}{|c|}{ Test 3} & \multirow{2}{*}{$\begin{array}{c}\text { Hypermnesia } \\
\text { (Test } 3-\text { Test } 1 \text { ) }\end{array}$} \\
\hline & & $M$ & $S D$ & $M$ & $S D$ & $M$ & $S D$ & \\
\hline \multicolumn{9}{|c|}{ Experiment 1} \\
\hline \multirow[t]{2}{*}{ Young } & Immediate & 17.30 & 4.23 & 17.60 & 4.32 & 18.40 & 4.15 & 1.10 \\
\hline & Delay & 16.40 & 4.78 & 17.05 & 5.52 & 18.60 & 6.80 & 2.20 \\
\hline \multirow[t]{2}{*}{ Old } & Immediate & 13.45 & 3.91 & 11.90 & 2.63 & 10.65 & 2.77 & -2.80 \\
\hline & Delay & 13.25 & 4.60 & 12.20 & 5.32 & 11.85 & 5.99 & -1.40 \\
\hline \multicolumn{9}{|c|}{ Experiment 2} \\
\hline \multirow[t]{2}{*}{ Young } & Fill & 22.10 & 4.65 & 25.60 & 6.13 & 27.00 & 7.60 & 4.90 \\
\hline & No fill & 18.70 & 7.07 & 24.30 & 6.11 & 26.40 & 7.12 & 7.70 \\
\hline \multirow[t]{2}{*}{ Old } & Fill & 18.30 & 4.21 & 19.00 & 2.49 & 19.50 & 3.06 & 1.20 \\
\hline & No fill & 15.30 & 4.21 & 14.60 & 3.57 & 16.50 & 4.45 & 1.20 \\
\hline
\end{tabular}

for young adults, recall increased across test trials $(M \mathrm{~s}=$ $16.85,17.08$, and 18.50 for Tests 1,2 , and 3 , respectively), whereas for older adults performance decreased across trials $(M \mathrm{~s}=13.35,12.05$, and 11.25 for Tests 1,2 , and 3, respectively). Planned comparisons, collapsing across interval (this factor was not significant in the overall ANOVA), revealed an increase in recall performance from Test 1 to Test 3 for young adults $[t(39)=-3.66, S E=.45]$ and a decrease in recall from Test 1 to Test 3 for older adults $[t(39)=3.84, S E=.55]$. No other effects were significant.

Table 1 reveals that older adults recalled fewer items on the first retrieval attempt than did young adults $(M \mathrm{~s}=$ 13.35 and 16.85 , respectively). This can be problematic in that young adults might recall more items, and at a faster rate, than older adults, leaving young adults more time to retrieve additional items, thereby producing greater reminiscence (cf. the total time hypothesis; Roediger \& Thorpe, 1978). A common procedure used in aging research to address this issue is to ensure equivalent acquisition by all participants (e.g., Kausler, 1994). We chose not to do this for two reasons. First, to ensure equivalent levels, we would have had to provide older adults with more study time and/or trials, relative to young adults, and this might result in differential degrees of learning on easy-to-learn items (e.g., Kausler, 1994). That is, older adults might overlearn easier-to-learn items relative to young adults. Consequently, there would result an underestimation of the true extent of age-related differences in hypermnesic recall. A second reason for not equating acquisition levels is that small and/or inconsistent correlations have been reported between initial recall levels and the number of items recalled on subsequent tests (see, e.g., Madigan \& O'Hara, 1992; Payne, 1986; Roediger \& Payne, 1985).

To address the differential recall issue, we adopted two strategies. First, we constructed two post hoc samples by obtaining 20 young and 20 older adults from our original sample so as to equate individuals on Test 1 performance $(M=15.65)$. A $2 \times 3$ mixed ANOVA with age (young vs. old) varied between participants and test (Test 1 vs. Test 2 vs. Test 3 ) varied within participants revealed an effect of age $\left[F(1,38)=3.94, M S_{\mathrm{e}}=50.86\right]$ such that older adults recalled fewer items than did young adults $(M s=14.03$ and 16.62 , respectively). In addition, there was an interaction between test and age $[F(2,76)=14.87$, $M S_{\mathrm{e}}=3.83$ ] such that across trials older adults had a net loss of information ( $M \mathrm{~s}=15.65,13.35$, and 13.10 for Tests 1, 2, and 3, respectively), whereas young adults had a net increase $(M \mathrm{~s}=15.65,16.40$, and 17.80 for Tests 1 , 2 , and 3, respectively). Despite equivalent recall on Test 1, we still observed hypermnesia for young adults and failed to observe it for older adults.

Our second strategy was to construct post hoc samples in such a manner that mean recall performance on Test 1 by young adults $(n=18 ; M=13.17)$ was below that of older adults $(n=18 ; M=16.94)$. A $2 \times 3$ mixed ANOVA with age (young vs. old) varied between participants and test (Test 1 vs. Test 2 vs. Test 3 ) varied within participants revealed an interaction between test and age $[F(2,68)=$ $\left.17.20, M S_{\mathrm{e}}=3.77\right]$ such that recall decreased across trials for older adults $(M \mathrm{~s}=16.94,14.33$, and 13.61 for Tests 1,2 , and 3, respectively) and increased across trials for young adults $(M \mathrm{~s}=13.17,14.06$, and 15.11 for Tests 1 , 2 , and 3 , respectively). We still observed hypermnesia for young adults and failed to observe it for older adults, despite the greater Test 1 recall by older adults. Given the results from these two analyses, we are more confident in our finding that older adults do not produce hypermnesia and that this failure is not the result of differential recall levels on the initial recall attempt.

Reminiscence and forgetting. To understand better the dynamics of hypermnesic recall, we examined separately the components responsible for the phenomenon: reminiscence and forgetting (Table 2 ). We operationally defined reminiscence as the number of study items that were not recalled on Test 1 but were recalled on Test 2 (Tests 1 to 2) and the number of items that were not recalled on Test 2 but were recalled on Test 3 (Tests 2 to 3 ). Forgetting was defined as the number of items that were recalled on Test 1 but not on Test 2 (Tests 1 to 2) and the number of items that were recalled on Test 2 but not on Test 3 (Tests 2 to 3 ). 
Table 2

\begin{tabular}{|c|c|c|c|c|c|c|c|c|c|}
\hline \multirow[b]{3}{*}{ Age } & \multirow[b]{3}{*}{ Condition } & \multicolumn{4}{|c|}{ Test 1 to Test 2} & \multicolumn{4}{|c|}{ Test 2 to Test 3} \\
\hline & & \multicolumn{2}{|c|}{ Forgetting } & \multicolumn{2}{|c|}{ Reminiscence } & \multicolumn{2}{|c|}{ Forgetting } & \multicolumn{2}{|c|}{ Reminiscence } \\
\hline & & $M$ & $S D$ & $M$ & $S D$ & $M$ & $S D$ & $M$ & $S D$ \\
\hline \multicolumn{10}{|c|}{ Experiment 1} \\
\hline Young & Immediate & 1.65 & 1.14 & 1.95 & 1.67 & 1.10 & 0.97 & 1.90 & 1.41 \\
\hline & Delay & 2.30 & 1.69 & 2.80 & 1.94 & 1.30 & 1.08 & 2.85 & 2.16 \\
\hline \multirow[t]{2}{*}{ Old } & Immediate & 3.80 & 2.82 & 2.25 & 1.68 & 2.85 & 1.85 & 1.60 & 1.47 \\
\hline & Delay & 3.50 & 1.32 & 2.55 & 2.19 & 2.00 & 1.38 & 1.65 & 1.81 \\
\hline \multicolumn{10}{|c|}{ Experiment 2} \\
\hline \multirow[t]{2}{*}{ Young } & Fill & 3.00 & 1.63 & 6.50 & 5.62 & 2.80 & 1.32 & 4.20 & 2.78 \\
\hline & No fill & 1.70 & 1.42 & 7.30 & 6.98 & 2.70 & 2.00 & 4.80 & 3.94 \\
\hline \multirow[t]{2}{*}{ Old } & Fill & 4.80 & 1.81 & 5.50 & 2.59 & 3.30 & 2.06 & 3.80 & 1.69 \\
\hline & No fill & 4.10 & 2.13 & 3.40 & 1.43 & 2.10 & 1.66 & 4.00 & 2.75 \\
\hline
\end{tabular}

A $2 \times 2 \times 2$ mixed ANOVA with age (young vs. old) and interval (immediate vs. delay) varied between participants and test (Test 1, the number of "new" items that were retrieved between Tests 1 and 2 vs. Test 2 ; the number of new items that were retrieved between Tests 2 and 3) varied within participants revealed no significant difference between young and older adults and no effect of the interval manipulation. Thus, there was no age-related difference in reminiscence levels.

A similar analysis, with the number of items forgotten as the dependent measure, revealed a main effect of age such that there was greater forgetting by older adults relative to young adults ( $M \mathrm{~s}=3.04$ and 1.59 , respectively) $\left[F(1,76)=35.11, M S_{\mathrm{e}}=2.40\right]$. In addition, there was a main effect of test $\left[F(1,76)=13.61, M S_{\mathrm{e}}=2.94\right]$ such that more items were forgotten between Tests 1 and 2 than between Tests 2 and $3(M \mathrm{~s}=2.81$ and 1.81 , respectively). Finally, age interacted with interval $[F(1,76)=4.18$, $\left.M S_{\mathrm{e}}=2.40\right]$ such that older adults forgot more items when the interval was short than when it was long $(M \mathrm{~s}=$ 3.33 and 2.75 , respectively), whereas young adults forgot more items when the interval was long than when it was short ( $M \mathrm{~s}=2.30$ and 1.38 , respectively). No other effects reached the established significance level.

Intrusions. For two reasons we felt it was important to examine recall intrusions. First, intrusions might result in lowered hypermnesia by interfering with the retrieval of studied items (e.g., retrieval blocks; this would be output interference). This possibility is particularly relevant when one is examining age-related differences, because it has been shown that older adults are affected by output interference to a greater extent than young adults are (see, e.g., Taub \& Walker, 1970). Second, intrusions may be indicative of changes in response criteria (see, e.g., Roediger, Srinivas, \& Waddill, 1989). Thus, age-related differences in intrusion patterns would support a hypothesis of age-related differences in response criteria. To illustrate, a decrease across trials would suggest a more conservative reporting strategy, whereas an increase would indicate a relaxed strategy.

A planned comparison revealed more intrusions (Table 3) among older adults than among young adults $(M s=22.93$ vs. 10.55 , respectively) $[t(78)=-3.72$, $S E=3.33]$. Further, the interval manipulation had no ef-

Table 3

Mean Number of Extra List Intrusions and Repeats as a Function of Age, Interval, and Test in Experiments 1 and 2

\begin{tabular}{|c|c|c|c|c|c|c|c|c|c|c|c|c|c|}
\hline \multirow[b]{3}{*}{ Age } & \multirow[b]{3}{*}{ Condition } & \multicolumn{6}{|c|}{ Extra List } & \multicolumn{6}{|c|}{ Repeats } \\
\hline & & \multicolumn{2}{|c|}{ Test 1} & \multicolumn{2}{|c|}{ Test 2} & \multicolumn{2}{|c|}{ Test 3} & \multicolumn{2}{|c|}{ Test 1} & \multicolumn{2}{|c|}{ Test 2} & \multicolumn{2}{|c|}{ Test 3} \\
\hline & & $M$ & $S D$ & $M$ & $S D$ & $M$ & $\overline{S D}$ & $M$ & $S D$ & $M$ & $S D$ & $M$ & $S D$ \\
\hline \multicolumn{14}{|c|}{ Experiment 1} \\
\hline \multirow[t]{2}{*}{ Young } & Immediate & 1.25 & 0.91 & 1.85 & 1.63 & 2.30 & 1.57 & 1.60 & 1.90 & 1.05 & 1.50 & 0.80 & 1.44 \\
\hline & Delay & 2.40 & 1.64 & 3.45 & 2.98 & 4.00 & 2.97 & 0.95 & 1.19 & 1.00 & 0.92 & 0.55 & 0.61 \\
\hline \multirow[t]{2}{*}{ Old } & Immediate & 2.95 & 1.91 & 5.10 & 4.89 & 5.00 & 3.85 & 4.40 & 2.68 & 3.95 & 3.72 & 1.10 & 1.11 \\
\hline & Delay & 4.25 & 6.23 & 6.50 & 10.07 & 5.85 & 6.96 & 2.90 & 1.59 & 2.20 & 2.12 & 1.70 & 1.56 \\
\hline \multicolumn{14}{|c|}{ Experiment 2} \\
\hline \multirow[t]{2}{*}{ Young } & Fill & 1.60 & 1.90 & 1.50 & 1.78 & 1.50 & 2.17 & 1.30 & 1.25 & 1.70 & 1.57 & 1.80 & 1.40 \\
\hline & No fill & 1.30 & 1.83 & 1.50 & 1.78 & 1.50 & 2.17 & 0.30 & 0.48 & 1.10 & 1.10 & 0.60 & 1.08 \\
\hline \multirow[t]{2}{*}{ Old } & Fill & 1.50 & 1.08 & 1.80 & 1.55 & 1.60 & 1.96 & 2.90 & 1.91 & 2.60 & 3.13 & 2.80 & 3.19 \\
\hline & No fill & 1.30 & 2.16 & 2.10 & 3.28 & 1.80 & 3.74 & 2.70 & 3.02 & 1.70 & 1.57 & 1.40 & 1.17 \\
\hline
\end{tabular}


fect on intrusions $[t(78)=-.62, S E=3.60]$. To obtain a better understanding of the effect of intrusions on hypermnesic recall, we broke intrusions down into two types: extralist items (i.e., reported items not on the study list) and repetitions (i.e., items reported more than once within a 5-min recall period) and performed separate analyses for each type.

A $2 \times 2 \times 3$ mixed ANOVA, with age (young vs. old) and interval (short vs. long) varied between participants and test (Test 1 vs. Test 2 vs. Test 3 ) varied within participants, and with the number of extralist items as the dependent measure, revealed a main effect of age $[F(1,76)=$ $\left.6.23, M S_{\mathrm{e}}=55.50\right]$ such that older adults produced more extralist items than did young adults $(M \mathrm{~s}=4.94$ vs. 2.54 , respectively). No other effects reached the established significance level.

A similar analysis, with number of repetitions as the dependent measure, revealed a main effect of age $[F(1,76)=$ $\left.31.79, M S_{\mathrm{e}}=5.56\right]$ such that older adults repeated items within a recall trial more often than did young adults $(M \mathrm{~s}=2.71$ vs. 0.99 , respectively). There was a main effect of test $\left[F(2,152)=17.08, M S_{\mathrm{e}}=2.52\right]$ such that the greatest number of repetitions occurred on the first trial and decreased with subsequent trials $(M \mathrm{~s}=2.47,2.05$, and 1.04 for Tests 1,2, and 3, respectively). Age interacted with test $\left[F(2,152)=6.07, M S_{\mathrm{e}}=2.52\right]$; the decrease in repetitions was greater for older adults $(M \mathrm{~s}=3.65,3.08$, and 1.40 for Tests 1,2 , and 3, respectively) than for young adults $(M \mathrm{~s}=1.28,1.03$, and 0.65 , respectively). There was a main effect of interval $\left[F(1,76)=3.88, M S_{\mathrm{e}}=5.56\right]$ such that there were more repetitions when there was no intertest interval relative to when there was a 15 -min interval $(M \mathrm{~s}=2.15$ vs. 1.55 , respectively). Finally, there was an interaction between test and interval $[F(2,152)=$ 3.64, $M S_{\mathrm{e}}=2.52$ ] such that repetitions decreased to a greater extent across trials when the interval was short $(M \mathrm{~s}=3.00,2.50$, and 0.95 for Tests 1, 2, and 3, respectively) relative to when it was long $(M \mathrm{~s}=1.93,1.60$, and 1.13 for Tests 1,2 , and 3, respectively).

Given that we observed more intrusions and intertest forgetting among older adults than among young adults, one might speculate that there is a relationship between intrusions and intertest forgetting. To examine this possibility, we correlated intrusions (collapsing across tests) with the number of items forgotten (collapsing across tests) and found no relationship $(r=-.009)$. We then did a median split on intrusions to form two post hoc groups: low intrusion $(M=13.03)$ and high intrusion $(M=$ 63.00). The numbers of items forgotten by individuals in these two groups were 4.69 and 3.83 , respectively. Thus, we still failed to observe a relationship between the two variables. Finally, we formed two post hoc groups consisting of 10 individuals with the lowest number of intrusions (low-intrusion median; $M=1.90$ ) and 10 individuals with the highest number of intrusions (high-intrusion median; $M=50.00$ ). The numbers of items forgotten by individuals in these two groups were 4.20 and 4.40 , respectively. Once again, we failed to establish a relationship between intrusions and intertest forgetting. It thus appeared that the number of intrusions was not responsible for greater intertest forgetting among older adults.

\section{EXPERIMENT 2}

The failure to observe hypermnesia for older adults in Experiment 1 might have been due, in part, to low recall levels. In Experiment 2, we addressed this possibility by using pictures. Research has shown that young, as well as older, adults benefit (i.e., greater recall) when pictures, rather than words, are used as to-be-remembered stimuli (e.g., Winograd, Smith, \& Simon, 1982).

In addition to incrementing the recall levels, we examined the possibility that the age-related difference in hypermnesic recall might have resulted from age-related differences in the ability to rehearse information during intertest intervals (Shapiro \& Erdelyi, 1974). We refer to this as the differential rehearsal hypothesis. Another intriguing possibility was that the older adults might have been less successful at engaging in tacit retrieval attempts of the studied material (tacit retrieval hypothesis; Smith $\&$ Vela, 1991). We examined both possibilities by manipulating whether the intertest interval was filled with a secondary task.

If the differential rehearsal hypothesis or the tacit retrieval hypothesis is accurate, then filling the interval should reduce age-related differences in hypermnesic recall. Our reasoning was that older adults would be less likely to engage in rehearsal strategies during the intertest interval than would young adults, and consequently, filling the interval should have a greater impact on the young than on the older adults. On the other hand, if an age-related difference in hypermnesic recall would still be evident for individuals in the fill condition, the older adults' failure to exhibit hypermnesia in Experiment 1 would not have been due, in any large part, to age-related differences in the ability to maintain and/or engage in tacit retrieval attempts of information during the intertest interval.

\section{Method}

Participants. Twenty undergraduates (mean age $=20.40$ years; $S D=2.35$ ) enrolled in psychology classes at Central Michigan University and 20 community-dwelling older adult residents (mean age $=59.40 ; S D=8.53$ ) of New York City participated in the present experiment. The undergraduates participated to fulfill partial course requirements, and the older adults were paid $\$ 5$. The same five-point self-rating health scale that was administered in Experiment 1 yielded a mean rating of $1.70(S D=.80)$ for the young adults and $2.15(S D=.75)$ for the older adults $[t(38)=1.84, p<$ .07]. Education levels were 14.15 years $(S D=1.27)$ for the young adults and $13.9(S D=1.68)$ for the older adults $[t(38)=.53]$.

Stimuli and Apparatus. The stimuli consisted of 42 monochrome pictures (Snodgrass \& Vanderwart, 1980, norms) with each picture representing a four-letter, monosyllabic word. The mean 
frequency of occurrence in the English language of these stimuli was $49.31(S D=81.75)$, with a range of 0 to 431 (Kučera \& Francis, 1967). Each normed picture was enlarged by $200 \%$ and pasted onto the backside of a $3 \times 5$ in. index card.

The participants in the fill condition were asked to solve a computer version of the Tower of Hanoi puzzle (Davis, Bajszar, \& Squire, 1995 ) with a default setting of five rings. The participant's task was to move the rings (with the mouse) from the left side of the monitor to the opposite side with the restrictions that only one ring could be moved at a time and that a larger ring could not be placed on top of a smaller ring. A 1-min distractor task consisted of counting backwards, by threes, from an experimenter-provided threedigit number. Finally, a tape recorder was used to record free recall reports.

Procedure. The procedure was similar to that in Experiment 1, with two exceptions. First, MEL was not used to control the stimulus presentation. Instead, the participants were asked to turn the index cards over, one at a time, when prompted by the experimenter. The second difference was that in Experiment 2 all the participants had 15-min intertest intervals during which they were required to work on the Tower of Hanoi puzzle (the fill condition) or to think about study list items (the no-fill condition).

\section{Results and Discussion}

A significance level of .05 was adopted for all statistical tests unless noted otherwise, and all comparisons were planned and two-tailed.

Recall performance. A $2 \times 2 \times 3$ mixed ANOVA with age (young vs. old) and interval (fill vs. nofill) varied between participants and test (Test 1 vs. Test 2 vs. Test 3) varied within participants, using the number of correctly recalled items as the dependent measure (see Table 1), revealed a main effect of age $[F(1,36)=23.92$, $\left.M S_{\mathrm{e}}=58.28\right]$ such that the young adults correctly recalled more study items than did the older adults $(M \mathrm{~s}=$ 24.02 and 17.20 , respectively). This pattern replicated the pattern observed in Experiment 1, except that recall levels were substantially higher in the present experiment. Note that recall by older adults in Experiment 2 approximated that of young adults in Experiment $1(M \mathrm{~s}=17.20$ and 17.56 , respectively). By using pictures, we successfully increased the recall levels from those of Experiment 1 for both age groups.

There was a main effect of test such that recall increased across trials $\left[F(2,72)=12.61, M S_{\mathrm{e}}=11.32\right]$ $(M \mathrm{~s}=18.60,20.88$, and 22.35 for Tests 1,2 , and 3, respectively). There was a marginal effect of interval $[F(1,36)=$ $\left.3.52, M S_{\mathrm{e}}=58.28, p<.07\right]$ such that more items were correctly recalled by individuals in the fill condition than in the no-fill condition (Ms $=21.92$ vs. 19.30 , respectively). However, this effect may have been the result of initial differences on Test 1 prior to the first filled/unfilled interval. There was an interaction between age and test $\left[F(2,72)=6.92, M S_{\mathrm{e}}=11.32\right]$ such that recall increased across trials for young adults $(M s=20.40,24.95$, and 26.70 for Tests 1,2 , and 3, respectively) but not for older adults $(M \mathrm{~s}=16.80,16.80$, and 18.00 for Tests 1 , 2 , and 3 , respectively). Planned comparisons revealed greater recall on Test 3 than on Test 1 for the young adults $[t(19)=-3.55, S E=1.77]$ and no difference be- tween Tests 3 and 1 for the older adults $[t(19)=-1.74$, $S E=.69]$. No other effects reached the established significance level.

As in Experiment 1, we observed an age-related difference in recall performance on Test $1(M \mathrm{~s}=16.80$ and 20.40 for the older and young adults, respectively). To address this issue, we adopted the same strategies that we used in Experiment 1. First, we matched the young and older adults on Test 1 performance $(M=16.56)$ in order to generate two post hoc samples of young $(n=9)$ and older adults $(n=9)$. We performed a $2 \times 3$ mixed ANOVA with age (young vs. old) as a between-subjects variable and test (Test 1 vs. Test 2 vs. Test 3 ) as a within-subjects variable on data obtained from these two groups. The analysis revealed a main effect of age $\left[F(1,16)=9.27, M S_{\mathrm{e}}=\right.$ 64.03] such that the older adults recalled fewer items than did the young adults $(M \mathrm{~s}=16.44$ and 23.07 , respectively). There was also a main effect of test $[F(2,32)=$ $\left.11.71, M S_{\mathrm{e}}=13.12\right]$ such that recall increased across trials $(M \mathrm{~s}=16.56,20.44$, and 22.28 for Tests 1,2 , and 3, respectively). Finally, there was an interaction between age and test $\left[F(2,32)=11.69, M S_{\mathrm{e}}=13.12\right]$ such that there was little change in recall performance across trials for the older adults $(M \mathrm{~s}=16.56,16.00$, and 16.78 for Tests 1, 2, and 3, respectively), whereas for the young adults recall increased across trials $(M s=16.56,24.89$, and 27.78 for Tests 1,2 , and 3, respectively). Thus, given equivalent recall levels on the first trial, we still failed to observe hypermnesia for older adults.

Our second procedure was to generate post hoc samples in such a way that the older adults had better recall on Test 1 than did the young adults. We generated two groups of 9 older adults (mean recall $=19.20$ ) and 9 young adults (mean recall $=15.60$ ). A $2 \times 3$ mixed ANOVA was performed with age (young vs. old) manipulated between participants and test (Test 1 vs. Test 2 vs. Test 3) manipulated within participants. The analysis revealed a main effect of test $\left[F(2,36)=10.22, M S_{\mathrm{e}}=12.82\right]$ such that recall increased across trials $(M \mathrm{~s}=17.40,21.00$, and 22.35 for Tests 1, 2, and 3, respectively). There was an interaction between age and test $[F(2,36)=10.01$, $\left.M S_{\mathrm{e}}=12.82\right]$ such that the older adults exhibited relatively constant recall levels across trials $(M \mathrm{~s}=19.20$, 18.90 , and 19.40 for Tests 1,2 , and 3, respectively), whereas recall increased across trials for the young adults $(M \mathrm{~s}=15.60,23.10$, and 25.30 for Tests 1,2 , and 3, respectively). Despite the greater recall among the older adults than among the young adults on the first recall trial, we still failed to observe hypermnesia for the older adults.

Reminiscence and forgetting. Presented in Table 2 are the mean reminiscence and forgetting levels. A $2 \times$ $2 \times 2$ mixed ANOVA, with age (young vs. old) and interval (fill vs. no fill) varied between participants and test (Tests 1-2 vs. Tests 2-3) varied within participants, using as the dependent measure the number of reminisced items, revealed an effect of test $\left[F(1,36)=6.28, M S_{\mathrm{e}}=\right.$ 6.93] such that reminiscence was greater from Test 1 to 
Test $2(M=5.68)$ than it was from Test 2 to Test $3(M=$ 4.20). No other effects were significant. The young adults in the present experiment exhibited a substantially greater amount of total reminiscence $(M=11.40)$ than did the young adults in Experiment 1 (delay condition; $M=$ $5.65)[t(38)=-2.63, S E=2.19, p<.01]$. Similarly, the older adults in the present experiment exhibited more total reminiscence $(M=8.35)$ than did the older adults in Experiment $1(M=4.20)[t(38)=-4.02, S E=1.03$, $p<.001]$. Despite this increase in reminiscence, we still failed to observe hypermnesia for the older adults.

A similar analysis, with the number of forgotten items as the dependent measure, revealed an effect of age $\left[F(1,36)=5.32, M S_{\mathrm{e}}=3.95\right]$ such that the older adults forgot more items than did the young adults $(M \mathrm{~s}=3.58$ and 2.55 , respectively). There was a marginally significant effect of test $\left[F(1,36)=3.86, M S_{\mathrm{e}}=2.36, p<.06\right]$ such that more items were forgotten between Tests 1 and $2(M=3.40)$ than between Tests 2 and $3(M=2.73)$. Furthermore, there was an interaction between test and age $\left[F(1,36)=9.78, M S_{\mathrm{e}}=2.36\right]$ such that more forgetting occurred for the older adults than for the young adults, between Tests 1 and $2(M \mathrm{~s}=4.45$ and 2.35 , respectively) but not between Tests 2 and $3(M \mathrm{~s}=2.70$ and 2.75 , respectively). Finally, there was a marginally significant effect of interval $\left[F(1,36)=3.45, M S_{\mathrm{e}}=3.95\right.$, $p<.07]$ such that more items were forgotten when the interval was filled relative to when it was not $(M \mathrm{~s}=3.48$ and 2.65, respectively). This outcome was expected, because individuals in the fill condition could not, to the same extent as those in the no-fill condition, rehearse items and consequently maintain them in memory. No other effects were significant.

Intrusions. Planned comparisons revealed more intrusions (Table 3 ) among the older adults than among the young adults $(M \mathrm{~s}=12.05$ and 7.05 , respectively) $[t(38)=$ $-2.24, S E=2.23$ ]. As noted in Experiment 1, a potential contributing factor to intertest forgetting may be output interference (e.g., extralist items and repetitions). To better understand the contribution of output interference to hypermnesic recall, we examined the reporting of extralist items and repetitions separately.

A $2 \times 2 \times 3$ mixed ANOVA with age (young vs. old) and interval (fill vs. no fill) varied between participants and test (Test 1 vs. Test 2 vs. Test 3 ) varied within participants, and with the number of reported extralist items as the dependent measure, revealed no significant effects. A similar analysis, with the number of repeated items as the dependent measure, revealed that the older adults repeated items more frequently than did the young adults $(M \mathrm{~s}=2.40$ and 1.23 , respectively) $[F(1,36)=6.56$, $\left.M S_{\mathrm{e}}=6.58\right]$, a finding which replicated that of Experiment 1 . No other effects reached the established significance level.

As in Experiment 1, we examined the relationship between intrusions and intertest forgetting. A correlation between these two variables revealed no significant rela- tionship $(r=.26, p<.10)$. We then did a median split on intrusions to form a low-intrusion group $(M=7.58)$ and a high-intrusion group $(M=24.57)$. The mean numbers of items forgotten by individuals in these two groups were 5.91 and 6.86, respectively. Again, we failed to observe a difference in the number of items forgotten even though there was a large difference in the number of reported intrusions. Finally, we formed two additional post hoc groups with the 10 individuals who produced the fewest intrusions $(M=3.00)$ making up one group and the 10 individuals who produced the greatest number of intrusions ( $M=21.50)$ making up the other group. We failed to find a difference in the number of forgotten items between these two groups ( $M \mathrm{~s}=4.90$ and 6.40 , respectively). Thus, as in Experiment 1, we found no relationship between intrusions and intertest forgetting.

\section{GENERAL DISCUSSION}

Our goal was to determine whether there might be age-related differences in hypermnesic recall. In the present study, we failed to observe hypermnesia for older adults when using words (Experiment 1) as well as pictures (Experiment 2), though we did observe the phenomenon for the young adults in both experiments. The failure to observe hypermnesia for the older adults could have been the result of age-related differences in reminiscence and/or intertest forgetting. We examined each of these hypermnesic recall components, as discussed below.

Our first expectation, that there would be little agerelated difference in reminiscence, was supported (Experiments 1 and 2). Furthermore, having a 15-min intertest interval (vs. no interval) did not affect reminiscence levels for either the young or the older adults (Experiment 1). In Experiment 2, we failed to observe hypermnesic recall for the older adults despite an increase in recall and reminiscence levels from those of Experiment 1. Finally, filling the intertest interval with a secondary task did not have an effect for either age group (Experiment 2).

Our second expectation, that there would be greater intertest forgetting among older adults than among young adults, was supported (Experiments 1 and 2). Furthermore, the older adults forgot more items when there was no intertest interval than when there was a 15 -min interval, whereas the young adults showed the reverse pattern (Experiment 1). In Experiment 2, we found a marginal effect of filling the intertest interval with a secondary task such that there was greater intertest forgetting for both the old and the younger adults relative to when the interval was not filled. In general, most intertest forgetting occurred between Tests 1 and 2 (Experiments 1 and 2), with the age-related difference in intertest forgetting's being greatest between Tests 1 and 2 (Experiment 2). One explanation for the age-related difference's being greater between Tests 1 and 2 is that the older adults did not engage in elaborative processing to the same extent as the young adults did when encoding study list items. As McDaniel 
et al. (1998) have noted, relational processing plays an important role in early retrieval attempts in a multitest paradigm.

There are several possible explanations for why the older adults produced more intertest forgetting. One possibility is tied to the observation that the older adults reported more intrusions (extralist items and repetitions) than the young adults did. If intertest forgetting is largely the result of output interference (e.g., intrusions), it follows that because older adults produce more intrusions they should also produce more intertest forgetting. This was the case, but when three formal analyses were performed to determine the relationship between these two variables, no relationship was uncovered. There may be some other process(es) and/or mechanism(s) that underlie both intrusions and intertest forgetting.

A second possibility is that the secondary task, being visual in nature, interfered with processing of the visual study list items, and that this occurred more so for older adults than for young adults. One could counter this assertion by arguing that the amount of hypermnesia observed for older adults should be greater when the intertest interval is not filled (the no-fill condition of Experiment 2) relative to when it is filled (fill condition of Experiment 2). In the present study, we found the same amount of hypermnesia for older adults in both conditions. Furthermore, we failed to observe an interaction between interval and age. Thus, on two counts, this proposed explanation does not hold up.

Finally, a third possibility, and one that seems most reasonable given the present findings, is that older adults do not reinstate cues at test as efficiently as young adults. Raaijmakers and Shiffrin (1980) used the term incrementing to refer to a retrieval process in which an item, once retrieved, has an increased likelihood of being retrieved in the future. Further, successful retrievals increase the associative strength between retrieved items and the cues that were used to probe memory at the time when the item was retrieved. As noted by McDaniel, Kowitz, and Dunay (1989), the likelihood of retrieving an item at some later point in time, given an initial retrieval, depends on reinstatement of the memory cue(s) present when the item was first recalled. McDaniel et al. (1998) suggest that this increment in the likelihood of retrieving an item will be greater for information that has been relationally encoded relative to information that has received item-specific processing. Furthermore, these authors suggest that intertest forgetting will be reduced as a result of this incremental process. It appears that cue reinstatement at test increases the likelihood of retrieving items and that relational processing plays an important role in this process. Given that older adults have a more difficult time engaging relational processes (e.g., Witte et al., 1990), it is reasonable to assume that older adults in the present study did not reinstate cues at retrieval as effectively as young adults. Consequently, we would expect greater in- tertest forgetting by older adults, as was observed in Experiments 1 and 2 of the present study.

The present findings reveal that intertest forgetting plays a critical role in the failure to observe hypermnesia for older adults. It is unclear why older adults produced more intertest forgetting. The present findings suggest that intertest forgetting is not related to the frequency of intrusions (Experiments 1 and 2), to the length of the intertest interval (Experiment 1), or to whether the interval is filled or not (Experiment 2). Clearly, more work needs to be done to determine why there is an age-related difference in intertest forgetting in a multitrial free-recall paradigm.

\section{REFERENCES}

BURNS, D. J. (1993). Item gains and losses during hypermnesic recall: Implications for the item-specific and relational information. Journal of Experimental Psychology: Learning, Memory, \& Cognition, 19, 163-173.

Craik, F. I. M., \& Tulving, E. (1975). Depth of processing and the retention of words in episodic memory. Journal of Experimental Psychology: General, 104, 268-294.

Davis, H. P., BaJszar, G. M., \& SQuire, L. R. (1995). Colorado neuropsychology tests: Explicit memory, implicit memory, and problem solving. Colorado Springs, CO: Colorado Neuropsychology Tests Co.

Ebinghaus, H. (1964). Memory: A contribution to experimental psychology. New York: Dover. (Original work published 1885)

ERDELYI, M. H. (1982). A note on the level of recall, level of processing, and imagery hypotheses of hypermnesia. Journal of Verbal Learning \& Verbal Behavior, 21, 656-661.

ERDELYI, M. H. (1996). The recovery of unconscious memories: Hypermnesia and reminiscence. Chicago: University of Chicago Press.

HunT, R. R., \& MCDANIEL, M. A. (1993). The enigma of organization and distinctiveness. Journal of Memory \& Language, 32, 421-445.

KAUSLER, D. H. (1994). Learning and memory in normal aging. San Diego: Academic Press.

Klein, S. B., Loftus, J., Kinlstrom, J. F., \& Aseron, R. (1989). Effects of item-specific and relational information on hypermnesic recall. Journal of Experimental Psychology: Learning, Memory, \& Cognition, 15, $1192-1197$.

Koriat, A., Ben-Zur, H., \& ShefFer, D. (1988). Telling the same story twice: Output monitoring and age. Journal of Memory \& Language, 27, 23-39.

KuČERA, H., \& FrANCIS, W. N. (1967). Computational analysis of presentday American English. Providence, RI: Brown University Press.

Madigan, S., \& O'HaRA, R. (1992). Initial recall, reminiscence, and hypermnesia. Journal of Experimental Psychology: Learning, Memory, \& Cognition, 18, 421-425.

McDaniel, M. A., Kowitz, M. D., \& Dunay, P. K. (1989). Altering memory through recall: The effects of cue-guided retrieval processing. Memory \& Cognition, 17, 423-434.

McDaniel, M. A., Moore, B. A., \& Whiteman, H. L. (1998). Dynamic changes in hypermnesia actoss early and late tests: A relational/itemspecific account. Journal of Experimental Psychology: Learning, Memory, \& Cognition, 24, 173-185.

PAYNe, D. G. (1986). Hypermnesia for pictures and words: Testing the recall level hypothesis. Journal of Experimental Psychology: Learning, Memory, \& Cognition, 12, 16-29.

PAYNE, D. G. (1987). Hypermnesia and reminiscence in recall: A historical and empirical review. Psychological Bulletin, 101, 5-27.

RaAiJMAKers, J. G. W., \& ShIFFrIN, R. M. (1980). SAM: A theory of probabilistic search of associative memory. In G. H. Bower (Ed.), The psychology of learning and motivation (Vol. 14, pp. 207-262). New York: Academic Press. 
RoEDIGER, H. L., III (1982). Hypermnesia: The importance of recall time and asymptotic level of recall. Journal of Verbal Learning \& Verbal Behavior, 21, 662-665.

RoEdiger, H. L., III, \& Challis, B. H. (1989). Hypermnesia: Improvements in recall with repeated testing. In C. Izawa (Ed.), Current issues in cognitive processes: The Tulane Floweree Symposium on cognition (pp. 175-199). Hillsdale, NJ: Erlbaum.

ROEDIGER, H. L., III, \& PAYNE, D. G. (1985). Recall criterion does not affect recall level or hypermnesia: A puzzle for generate/recognize theories. Memory \& Cognition, 13, 1-7.

Roediger, H. L., III, Payne, D. G., Gillespie, G. L., \& Lean, D. S (1982). Hypermnesia as determined by level of recall. Journal of Verbal Learning \& Verbal Behavior, 21, 635-655.

Roediger, H. L., III, SRINIVAs, K., \& Waddill, P. (1989). How much does guessing influence recall? Comment on Erdelyi, Finks, and FeiginPfau. Journal of Experimental Psychology: General, 118, 255-257.

ROEDIGER, H. L., III, \& THORPE, L. A. (1978). The role of recall time in producing hypermnesia. Memory \& Cognition, 6, 296-305.

ShaPIRO, S. R., \& ERDELYI, M. H. (1974). Hypermnesia for pictures but not for words. Journal of Experimental Psychology, 103, 1218-1219.

SMrth, S. M., \& Vela, E. (1991). Incubated reminiscence effects. Memory \& Cognition, 19, 168-176.
SNODGRass, J. G., \& VANDERWART, M. (1980). A standardized set of 260 pictures: Norms for name agreement, image agreement, familiarity, and visual complexity. Journal of Experimental Psychology: Human Learning \& Memory, 6, 174-215.

TAUB, H. A., \& WALkER, J. B. (1970). Short-term memory as a function of age and response interference. Journal of Gerontology, 25, 177-183.

Toglia, M. P., \& BatTiG, W. F. (1978). Handbook of semantic word norms. Hillsdale, $\mathrm{NJ}$ : Erlbaum.

Tulving, E. (1962). Subjective organization in free recall of "unrelated words." Psychological Review, 69, 344-354.

TulviNG, E. (1964). Intratrial and intertrial retention: Notes toward a theory of free recall verbal learning. Psychological Review, 71, 219-237.

Winograd, E., Smith, A. D., \& Simon, E. W. (1982). Aging and the picture superiority effect in recall. Journal of Gerontology, 37, 70-75.

Witte, K. L., FreUnd, J. S., \& Sebby, R. A. (1990). Age differences in free recall and subjective organization. Psychology \& Aging, 5, 307-309.

Worden, P. E., \& Meggison, D. L. (1984). Aging and the categoryrecall relationship. Journal of Gerontology, 39, 322-324.

(Manuscript received November 2, 1998; revision accepted for publication July 16, 1999.) 